\title{
How to Share Korean Language and Culture with Pre-Service Teachers in the United States
}

\author{
Yong Joon Park ${ }^{1} \&$ Youjin Yang ${ }^{2}$ \\ ${ }^{1}$ Bayh College of Education, Indiana State University, Terre Haute, IN, USA \\ ${ }^{2}$ Education Department, St. Mary-of-the-Woods College, St Mary of the Woods, IN, USA \\ Correspondence: Yong Joon Park, Department of Early, Elementary, and Special Education, Indiana State \\ University, Terre Haute, IN 47809, USA. Tel: 1-812-237-7892. E-mail: ypark4@indstate.edu
}

\author{
Received: March 14, 2013 Accepted: April 10, 2013 Online Published: April 26, 2013 \\ doi:10.5539/ies.v6n5p78 \\ URL: http://dx.doi.org/10.5539/ies.v6n5p78
}

\begin{abstract}
Many teacher educators believe that pre-service teachers should be aware of their future classroom environment including students who have linguistically and culturally diverse backgrounds. This paper is a description of how two teacher educators helped pre-service teachers develop their multicultural awareness in preparation for careers in Early Childhood Education. 74 pre-service teachers participated in the 8-week-long intervention, learning about 8 different topics of Korean language and culture during the 2012 Institute of Early Childhood Education Forum. The authors' and presenters' reflections, and participants' survey data were collected, analyzed, and summarized for the intervention. The study results indicated that considering a variety of instructional strategies could help teacher educators prepare a forum to teach about Korean language and culture in Early Childhood Education and that pre-service teachers could receive benefits from the information offered.
\end{abstract}

Keywords: Korean language \& culture, the cycle of action research, forum, early childhood education

\section{Introduction}

Schools have become more racially, ethnically, and linguistically diverse (Watanabe, 2010). Many teacher educators indicate that pre-service teachers should be aware of their future classroom environment, including students who have linguistically and culturally diverse backgrounds. As society becomes culturally and globally interconnected and rapid changes in technology continue, many teacher education programs have gradually integrated current knowledge and skills of teaching for cultural diversity into their programs (Castro, 2010). For instance, many teacher education programs have recently emphasized practical experiences such as short or long-term study abroad programs with an emphasis on multicultural awareness, and many teacher educators have seen positive effects of these programs (Chieffo \& Griffiths, 2004; Franklin, 2010; Woolf, 2010). However, those practical experiences normally ask pre-service teachers to invest plenty of time and expense. Ray, Bowman, and Robbins (2006) studied the content of websites for 226 teacher preparation programs in colleges and universities in the USA and found that only 7\% required a student internship in a setting described as "diverse" or "multicultural" or suggested the program expects the student teacher will gain experience with children of color, second language learners, children from many cultures and ethnicities, immigrants, children in poverty, or students with special needs. That means that in many teacher preparation programs, pre-service teachers may not have enough experience to face the current multicultural and globalized school environment.

As teacher educators, we conceived of a supplemental tool of multicultural and global awareness for our pre-service teachers and prepared the 2012 Institute of Early Childhood Education Forum (the 2012 IECEF) after reviewing recent studies on multicultural education in both schools and teacher preparation programs. In this paper, we summarize the process of the 2012 IECEF using the action research cycle.

\section{Background}

\subsection{Multicultural Education at Schools in a Global Society}

There are a variety of instructional strategies of multicultural education for students at schools. One of them would be hosting events or inviting guest speakers from different cultures. For instance, Malakolunthu (2000) studied "Vision Schools" in Malaysia which included a new concept that brought within its common premises the vernacular primary schools of Malays, Chinese, and Indians and concluded that the vision schools were 
established to foster racial integration among students by sharing of common facilities and jointly hosting school events, however, school administrators' appropriate leaderships should be improved. Using the practical hands-on experiences would be another good instructional strategy. Thurston (2004) investigated the impact of interaction through sixty-six 11-12-year-old Scottish students' gathering the data through questionnaires, interviews, direct observation, digital images and video from their local community and engaging in remote reciprocal presentations with students in USA on aspects of multicultural awareness in Scottish primary schools. Thurston found out some evidence of pre-post project gains in the complexity of the children's perceptions of their community environment, the ethnicity of their community, their own ethnicity, and news images. Storytelling or presenting a topic appropriately could be a good strategy. For example, Chongruksa, Prinyapol, Wadeng, \& Padungpong (2010) examined the efficacy of storytelling on multicultural understanding and respect among students of the two ethnic groups such as Thai-Buddhist and Thai-Muslim students in Thailand. The authors found out that the strategic storytelling program, which incorporated non-prejudice and intergroup contact factors, fostered multicultural understanding and respect among the two ethnic groups.

Thus, considering a variety of multicultural education at schools in a global society, it is important for teacher educators to be knowledgeable about the culture and able to use a variety of instructional strategies and activities which are appropriate or connected to the current schools. Therefore, in this study, the authors selected a variety of instructional strategies such as hosting guest speakers, using technology-based instruction, hands-on activities and discussion time among presenters and pre-service teachers. However, there were very few studies of how to provide pre-service teachers multi-cultural education systematically.

\subsection{Pre-Service Teachers' Multi-Cultural Awareness}

Are pre-service teachers in the USA ready to deal with multicultural issues in a rapidly changing global society? Empirical studies of pre-service teachers' cultural diversity awareness have had positive results. Milner, Flowers, Moore, Moore, and Flowers (2003) evaluated 99 pre-service teachers' general cultural diversity awareness using the Cultural Diversity Awareness Inventory and concluded that teacher education programs including multiculturalism and diversity helped pre-service teachers develop more multicultural competencies and improve their attitudes about cultural diversity. Trent, Kea, and Oh (2008) reviewed 46 studies on the incorporation of multicultural education in pre-service general and special education teacher preparation programs from 1997 to 2006 and concluded that teacher preparation programs should provide pre-service teachers with current information about how to support culturally and linguistically diverse learners. Teacher educators themselves should be knowledgeable about the information through enough practical experiences and comprehension. Castro (2010) studied pre-service teachers' views of cultural diversity published in peer-reviewed journals from 1985 to 2007 and found more positive attitudes about teaching culturally diverse students in the studies as time went on. This was in spite of pre-service teachers' persistent difficulties of understanding cultural diversity such as their inability to teach children from cultural and religious backgrounds that differ from their own or to communicate with children and families from diverse backgrounds.

\subsection{Developing Multicultural Education for Pre-Service Teachers}

Collaboration among teacher educators and appropriate course development and instructional strategies are fundamental to effective multicultural education. Rogers et al. (1993) created and conducted a multi-part seminar over a period of three academic years which focused on multicultural concerns and international perspectives in the curricula. Teacher educators from different disciplines collaborated after completing the brainstorming stage in which they identified interdisciplinary interests and obtained suggested themes for the seminar. Kim, Park, Cho, and Kim (2013) conducted several meetings and workshops to encourage interdisciplinary partnership among teacher educators and then built a university-deaf school partnership to aid in understanding deaf students of mathematics and technology. They shared their cultural experiences with the deaf students with pre-service teachers and other faculty members through local and national conference presentations and publications. The 2012 IECEF described in this paper was planned through collaboration among faculty members, teachers, and pre-service teachers.

Course preparation and teaching strategies are just as important as the collaboration in teacher education. Gorski (2009) examined the syllabi from multicultural teacher education courses taught across the United States and revealed that most of the courses were designed to prepare pre-service teachers with pragmatic skills and personal awareness. McAllister and Irvine (2000) examined three process-oriented models that have been used to describe and measure the development of racial identity and cross-cultural competence, including Helms' model of racial identity development, Banks' Typology of Ethnicity, and Bennet's Developmental Model of Intercultural Sensitivity. McAllister and Irvine concluded that teacher educators should use various methods to 
foster change in pre-service teachers' thinking, attitudes, and behaviors regarding cultural diversity and focus more on the process of cross-cultural learning. Teacher educators' appropriate instructional strategies could be the most important factor in effective multicultural education. Brown (2004) investigated the relationship between instructional methodology and changes in resistance to cultural diversity sensitivity among 100 Caucasian pre-service teachers in a required junior-level cultural diversity course and found that the methodology (i.e., using pre-and post-test measures, reflective journals, reports based on 100 hours of urban field observations, and research papers) was useful to reduce resistance. Next, the procedures of the 2012 IECEF based on the cycle of action research was described.

\subsection{Action Research Cycle for the Structured Plans in this Study}

For the framework of this study, action research cycle was used for the procedure of practitioner research (or, more specifically, teacher research). The process of this study is based on the cycle of inquiry: planning-acting-observing-reflecting (Herr \& Anderson, 2005; Johnson, 2005). There are several multicultural education studies focusing on comparing two countries' or two ethnic groups' characteristics (Anxo, Rego, \& Nieto, 2000; Genç, Avest, Miedema, 2011; Chongruksa, Prinyapol, Wadeng, \& Padungpong, 2010; Thurston, 2004). In the process of developing the forum, one of the authors noticed that pre-service teachers often asked him about Korean language, culture, and education system in and out of class; after discussing these topics, these individuals became interested in comparing South Korea with the USA and finding out similarities and differences of Early Childhood Education between two countries. Many of them did not know much about Korean language and culture and said that they had had very few foreign-born teacher educators before. As Korean teacher educators in the USA, we had a plan to share our culture and language in terms of Early Childhood Education in the format of a forum.

As we acted to implement the plan, one of the authors obtained an internal grant to support the 2012 IECEF and invited an award-winning Korean teacher as a keynote speaker to make a presentation on the current Korean elementary school system including teacher's roles and Korean elementary students. Two Korean school teachers at a local Korean language and culture school were also invited to be presenters during the forum. Including the authors, there were five presenters for eight different sessions (see Appendix). In the beginning of preparation, a website for the 2012 IECEF was created including content such as the logo, electronic registration form, a video-clip, a poster, and a brochure for the forum.

In the third stage (observing the effects of action in the context in which it occurs) and the fourth stage (reflecting on these effects as a basis for further planning, subsequent action and so on through a succession of cycles), surveys completed by each participant and forum presenters' reflection form were distributed, analyzed, and summarized.

The purpose of this study was to describe how two teacher educators effectively shared Korean language and culture with pre-service teachers using an 8-week-long intervention of presentations on Korean language, culture and early childhood education in the 2012 IECEF. The Forum activities consisted of lectures and hands-on activities for eight different topics. The research questions are as follows:

1) How did the pre-service teachers evaluate the quality of the 2012 IECEF?

2) What did the pre-service teachers think of the effective instructional strategies used to deliver the 2012 IECEF?

3) What did the pre-service teachers like most and least about the 2012 IECEF?

4) What did the presenters think about the effectiveness of preparation and instructional strategies for the 2012 IECEF?

\section{Method}

\subsection{Participants and Site}

The participants for this study were 74 pre-service teachers enrolled in a teacher education program located in a Midwestern region of the USA. Seventy female and four male pre-service teachers participated in this study. For the ethnicity, 98\% were White and 2\% were Black or Hispanic. For their academic year, $2 \%$ were freshmen, $39 \%$ were sophomores, and $59 \%$ were juniors. There were dual majors such as elementary education and special education majors $(39 \%)$, elementary education majors only $(22 \%)$, elementary education majors with reading minors $(21 \%)$, elementary education majors with early childhood minors $(14 \%)$, and communication disorder majors $(2 \%)$. Participants voluntarily completed the early childhood education forum survey after each session. 
From a cultural-historical perspective, teacher educators, who initiate and coordinate programs and conduct studies, can also be considered participants (Spradley, 1980; Trent et al., 2008). Thus, the authors considered themselves participants in this study and presented topics at the forum. The two authors, South Koreans, have doctorate degrees in Early Childhood Education, taught young children, and have worked for teacher preparation programs. One was male and the other was female. Two other female presenters worked as early childhood education teachers at a Korean language and culture school near the university. Both of them studied Early Childhood Education. One was a South Korean who obtained her master's degree in Early Childhood Education and the other was a Taiwanese who was working on her Ph.D. in Early Childhood Education. The last female presenter has worked as an elementary school teacher in South Korea, obtained her master's degree in Elementary Education in South Korea, and came to the university as a visiting scholar in 2012. Her nationality was South Korean.

\subsection{Data Collection and Data Analysis}

The main data were collected from the Early Childhood Education Forum Survey. The collected quantitative data were analyzed using SPSS. The qualitative data were separately analyzed by both authors and the analyses were compared. The authors only accepted the data when their analyses of the categories matched. The two authors' and three other presenters' reflections were collected along with pre-service teachers' data from a survey they completed on the 2012 IECEF. The results of the survey data were combined and will be discussed in the discussion section of this paper.

\subsection{Instrumentation}

The authors created an Early Childhood Education Forum Survey to learn the pre-service teachers' evaluation of the forum. Using our knowledge about the forum, cultural diversity and early childhood education, we evaluated the items and the content of the survey and developed the final version of it. The survey was pilot-tested on 70 pre-service teachers to test its reliability level. The reliability analysis revealed Cronbach's alpha reliability score of .90 , which showed that the instrument was highly reliable. Pre-service teachers completed survey anonymously and voluntarily after each session of the 2012 IECEF. The first section of the survey contained six multiple choice questions about participants' opinions of the overall quality of the forum including instructional strategies and materials. All items were rated on a 5 point rating scale (i.e., very poor/not useful, poor/minimally useful, fair, good/useful, and very good/very useful). The second section of the survey included three open-ended questions about participants' comments or opinions of their favorite parts of the forum, the strengths and weaknesses of the forum, and suggestions for improvement. The authors also collected and summarized their reflections based on communication with both the presenters and the attendees before and after each session.

\section{Results}

Below, the outcomes of the pre-service teachers' survey data are summarized to answer the first three research questions. The outcomes of the presenters' survey data are summarized in the section about the fourth research question.

\subsection{Pre-Service Teachers' Evaluation of the 2012 IECEF}

As Table 1 shows, many pre-service teachers thought that the forum showed excellent quality $(M=4.45, S D=$ 0.724). In detail, hand-outs $(M=4.79, S D=.407)$, lectures $(M=4.69, S D=.547)$, and hands-on activities $(M=$ $4.43, S D=.853$ ) were all very useful in helping the attendees to understand Korean language and culture within Early Childhood Education. In addition, the forum provided the pre-service teachers with insights about multicultural awareness within early childhood education $(M=4.48, S D=0.689)$. 
Table 1. Summary of Pre-service Teachers' Evaluation of the 2012 IECEF

\begin{tabular}{|c|c|c|c|c|c|}
\hline Statistic & $\begin{array}{l}\text { Rating the } \\
\text { overall } \\
\text { quality of } \\
\text { the forum }\end{array}$ & $\begin{array}{l}\text { How useful were } \\
\text { the lectures of } \\
\text { understanding early } \\
\text { childhood education } \\
\text { of Korean language } \\
\text { and culture? }\end{array}$ & $\begin{array}{l}\text { How useful } \\
\text { were the } \\
\text { printed } \\
\text { handouts? }\end{array}$ & $\begin{array}{l}\text { How useful were } \\
\text { the hands-on } \\
\text { activities as the } \\
\text { tools in the } \\
\text { understanding } \\
\text { early childhood } \\
\text { education of } \\
\text { Korean language } \\
\text { and culture? }\end{array}$ & $\begin{array}{l}\text { Has this forum } \\
\text { given you new } \\
\text { viewpoints and } \\
\text { insights of } \\
\text { multicultural } \\
\text { awareness } \\
\text { within early } \\
\text { childhood } \\
\text { education? }\end{array}$ \\
\hline Min Value & 2 & 3 & 4 & 1 & 2 \\
\hline Max Value & 5 & 5 & 5 & 5 & 5 \\
\hline Mean & 4.45 & 4.69 & 4.79 & 4.43 & 4.48 \\
\hline Variance & .524 & .299 & .166 & .728 & .475 \\
\hline$S D$ & .724 & .547 & .407 & .853 & .689 \\
\hline $\begin{array}{l}\text { Total } \\
\text { Responses }\end{array}$ & 74 & 74 & 74 & 74 & 74 \\
\hline
\end{tabular}

Research Question 1. How did the pre-service teachers evaluate the quality of the 2012 IECEF?

For the overall quality of the forum, $56.8 \%$ of pre-service teachers $(n=42)$ thought that it was excellent, $32.4 \%$ $(n=24)$ considered it very good, $9.4 \%(n=7)$ thought that it was good, and only $1.4 \%(n=1)$ selected the option "fair." Nobody selected the option "poor." Regarding content quality or whether the forum provided the pre-service teachers with new viewpoints or insights about multicultural awareness within early childhood education, $56.8 \%$ of pre-service teachers thought that the presenters did so to a very great degree $(n=42), 33.8 \%$ $(n=25)$ to a great degree, $6.8 \%(n=5)$ to a moderate degree, and $1.4 \%(n=1)$ to a minimal degree.

These results indicate that the pre-service teachers who participated in the forum thought that it provided them with a good quality of education. In particular, the pre-service teachers thought that the forum presenters gave them new viewpoints or insights about multicultural awareness within early childhood education.

Research Question 2. What did the pre-service teachers think of the effective instructional strategies to deliver the 2012 IECEF?

The second question of the survey asked participants regarding the instructional strategies of the forum. In answer to this question, $81 \%$ of pre-service teachers thought that it featured a good ratio of lectures and hands-on activities $(n=60)$, only $2.8 \%(n=2)$ thought there were too many lectures or hands-on activities, and $16.1 \%(n=$ 12) of the participants indicated that the forum did not provide enough hands-on activities. As for usefulness of the lectures, $73 \%(n=54)$ thought that the lectures were a very useful overview, $23 \%(n=17)$ thought they were minimally useful, and $4 \%(n=3)$ were not certain. For the usefulness of the hands-on activities provided by the forum, $61.8 \%$ thought that they were very useful $(n=46), 24.3 \%(n=18)$ thought they were somewhat useful, $1.4 \%(n=1)$ thought they were minimally useful, $11.1 \%(n=8)$ were not certain about the usefulness, and $1.4 \%$ $(n=1)$ thought that they were not useful. For usefulness of handouts, $79.7 \%$ thought that the handouts were very useful $(n=59)$ and $20.3 \%(n=15)$ thought they were somewhat useful.

These results indicate that many pre-service teachers thought that the instructional strategies of using both lectures and hands-on activities were well balanced and the instructional strategies of using both lectures and hands-on activities with handouts were very useful to help them understand Korean language and culture within early childhood education.

Research Question 3. What did the pre-service teachers like the most and the least from the 2012 IECEF?

Three open-ended questions within the survey questionnaires were used to answer research question 3. The three questions were as follows:

1) What were the most favorite parts/things from the 2012 IECEF?

2) What were the least favorite parts/things from the 2012 IECEF?

3) What kinds of suggestions do you have for the next Institute of Early Childhood Education Forum? 
Not all the pre-service teachers answered these questions. Out of 74 pre-service students who attended the forum, 71 answered the question about their favorite things from the forum, 11 answered the question about their least favorite things, and 32 gave us other suggestions for future forums. Many pre-service teachers enjoyed the hands-on activities such as creating crafts, singing along with Korean children's songs and watching video clips of the songs. Some suggested more hands-on activities and less lecture format for future forums. The results are summarized in Table 2 .

Table 2. Summary of Most- and Least-liked Aspects of the 2012 IECEF

\begin{tabular}{|c|c|c|c|}
\hline & $\begin{array}{l}\text { Favorite Things from the } \\
\text { Forum }\end{array}$ & $\begin{array}{l}\text { Least Favorite Things } \\
\text { from the Forum }\end{array}$ & Other Suggestions \\
\hline \multirow{6}{*}{$\begin{array}{l}\text { Total } \\
\text { Participants }\end{array}$} & 71 pre-service teachers & 11 pre-service teachers & 32 pre-service teachers \\
\hline & $\begin{array}{l}\text { Hands-on activities such } \\
\text { as creating crafts, singing } \\
\text { along with Korean } \\
\text { children's songs and } \\
\text { video-clips of the songs ( } n \\
=35 \text { ) }\end{array}$ & $\begin{array}{l}\text { Not enough information } \\
\text { about the curriculum in } \\
\text { South Korea }(n=2)\end{array}$ & $\begin{array}{l}\text { More hands-on activities and less } \\
\text { lecture }(n=15)\end{array}$ \\
\hline & $\begin{array}{l}\text { Learning about the } \\
\text { Korean education system } \\
\text { and history of Korean } \\
\text { kindergarten }(n=20)\end{array}$ & $\begin{array}{l}\text { Unclear hand-outs or } \\
\text { Power point slides }(n=2)\end{array}$ & Slow and clear lecture $(n=3)$ \\
\hline & & Not enough time $(n=1)$ & $\begin{array}{l}\text { More question time for the forum }(n \\
=1)\end{array}$ \\
\hline & $\begin{array}{l}\text { New information such as } \\
\text { getting a great } \\
\text { understanding of another } \\
\text { culture }(n=10)\end{array}$ & & More videos $(n=1)$ \\
\hline & $\begin{array}{l}\text { Learning about Korean } \\
\text { language as a new } \\
\text { language }(n=6)\end{array}$ & & $\begin{array}{l}\text { More time for learning Korean } \\
\text { language }(n=2)\end{array}$ \\
\hline
\end{tabular}

\subsection{Presenters' Evaluation of the 2012 Institute of Early Childhood Education Forum}

Research Question 4. What did the presenters think about their effective preparation and instructional strategies for the 2012 IECEF participants?

Our efforts to introduce Korean language and culture as a part of cultural awareness, the technology-based advertisements used to promote the forum, the combination of hands-on activities (e.g., crafts and songs) and lectures (e.g., including video clips, Power point slides and hand-outs), inviting a variety of speakers (e.g., both from South Korea, Taiwan, and USA), and applying the action research cycle for the forum were good strategies for achieving our goal of effectively sharing Korean language and culture with pre-service teachers.

Technology-based advertisements. As the target audience for this forum was pre-service teachers who were normally very skillful with current technology devices and technology-based information, we used technology for effective advertisement. We created a website for the 2012 Institute of Early Childhood Education Forum within the university system and continued uploading the forum schedule with several pictures and a video clip. We also distributed an e-flyer about the forum through the university e-mail system and advertised the forum through the campus e-news and other educational websites. During the forum period, we did on-going promotions through the forum website such as uploading pictures after each session.

A variety of hands-on activities and lectures. Three presenters in addition to the authors conducted the sessions, which consisted of at least one hands-on activity and PowerPoint slides with hand-outs. If possible, we 
coordinated the presentations so that each presenter could select a different topic and activity (see Appendix A) based on the presenter's strength. We thought that various activities rather than lectures alone would interest the pre-service teachers in a different culture and language; however, the lectures were still an important tool to deliver information about each topic. As the attendees seemed to enjoy the activities and rated them highly, the combination of the hands-on activity and lecture was a good strategy.

A variety of guest speakers. We intentionally invited diverse guest speakers who worked in various education programs, including one elementary school teacher from South Korea and two local Korean language and culture school teachers who were also in teacher preparation programs in the USA. Thus we expected that the pre-service teachers could hear different voices and opinions about how to work with students from South Korea in the USA. Most speakers believed that their information was current and practical for the purpose of the pre-service teachers' understanding Korean language and culture within early childhood education.

The action research cycle. We used the framework of the action research cycle (Herr \& Anderson, 2005) for brainstorming the forum and conducting the procedures, and we believe that this cycle made us work efficiently and effectively in establishing the purpose, planning, implementing, and reflecting on the forum.

\section{Discussions}

\subsection{Quality of the 2012 Institute of Early Childhood Education Forum}

Based on participants' answers to the survey questions related to Research Question 1, we believe that many of the attendees thought that the forum was excellent. In particular, they thought that the hand-outs were very useful and that the forum sessions provided them very helpful lectures and hands-on activities to understand Korean language and culture. Finally, the forum provided the pre-service teachers with insights about multicultural awareness within early childhood education. Thus, we concluded that the overall quality of the forum was good or excellent and achieved our target goal. This implies that a forum format may help pre-service teachers obtain the insights of multicultural awareness within a limited time.

\subsection{Hands-on Activities vs. Lectures}

Each session normally consisted of a 30-minute lecture using PowerPoint slides and hand-outs, a 20-minute hands-on activity, and a 10-minute question and answer time. Based on the results of the survey questions related to Research Question 2, we believe that most of the pre-service teachers thought that the forum had a good ratio of lectures and hands-on activities; only 2 indicated there were too many lectures or hands-on activities, and only 12 thought that the forum did not provide enough hands-on activities. The possible explanation for this result is that almost half of the participants $(n=35)$ indicated that the hands-on activities were their favorite part of the forum and 15 participants suggested more hands-on activities for future forums. We understood these results to mean that the participants really enjoyed the hands-on activities and would like to have more time for them. However, we do not think that the forum format should be changed to have more hands-on activity time because the majority of pre-service teachers $(n=60)$ thought that the current format had a good ratio of lectures and hands-on activities. In addition, based on the presenters' reflections, the combination of hands-on activities and lectures seems to be a good one. Therefore, we concluded that the ratio of lectures and hands-on activities offered over the course of eight one-hour sessions is an appropriate forum format in teacher education for pre-service teachers.

\subsection{Additional Finding: Moral Education}

In addition, 20 pre-service teachers stated that their favorite thing from the forum was learning about the Korean education system and history of Korean kindergarten. For instance, when the keynote speaker visited three different early childhood education courses and presented her topic, Comparing Korean Elementary Education with United States Elementary Education, many pre-service teachers wondered what moral education meant in South Korea. Moral education is studied from first to twelfth grade. At the primary grade level (i.e., from first to third grade), the major content of moral education is about how to show good manners and attitudes while communicating or interacting with others. The presentation stimulated the pre-service teachers to discuss the value of educating children in morality as one of the major subjects at school. Many of them stated that the idea of moral education was very interesting. This implies that the comparison of education system between South Korea and the USA could motivate the pre-service teachers to participate in meaningful discussion.

\section{Conclusion}

We concluded that our action was meaningful for pre-service teachers who would work with racially, culturally, and linguistically diverse children in the USA. Based on our reflection, we believe that the action research cycle worked well for the forum preparation and future plans. Although many of the participants agreed that the ratio 
of lectures and hands-on activities was just right, some thought that future forums could be better with more hands-on activities rather than lectures, and some of them also thought that more time was necessary for each session. We may consider increasing the time limit for each session in future forums. For the future, we plan to select another country's culture and language to focus on through the lens of Early Childhood Education depending on possible funding and guest speakers. The findings of this study will be used to more effectively plan future forums to increase the number of participants and enhance their multicultural awareness.

\section{Acknowledgment}

This work was supported by the 2012 Richard Wiley Memorial Faculty Development Fund Award of Bayh College of Education, Indiana State University.

\section{References}

Anxo, M., Rego, S., \& Nieto, S. (2000). Multicultural/intercultural teacher education in two contexts: Lessons from the United States and Spain. Teaching and Teacher Education, 16(4), 413-427. http://dx.doi.org/10.1016/S0742-051X(00)00003-2

Brown, E. L. (2004). What precipitates change in cultural diversity awareness during a multicultural course? Journal of Teacher Education, 55(4), 325-340. http://dx.doi.org/10.1177/0022487104266746

Castro, A. J. (2010). Themes in the research on preservice teachers' views of cultural diversity: Implications for researching millennial preservice teachers. Educational Researcher, 39(3), 198-210. http://dx.doi.org/10.3102/0013189X10363819

Chieffo, L., \& Griffiths, L. (2004). Large-scale assessment of student attitudes after a short-term study abroad program. The Interdisciplinary Journal of Study Abroad, 5, 165-177.

Chongruksa, D., Prinyapol, P., Wadeng, Y., \& Padungpong, C. (2010). Storytelling: Program for multicultural understanding and respect among Thai-Buddhist and Thai-Muslim students. Procedia-Social and Behavioral Sciences, 5, 282-288. http://dx.doi.org/10.1016/j.sbspro.2010.07.089

Franklin, K. (2010). Long-term career impact and professional applicability of the study abroad experience. The Interdisciplinary Journal of Study Abroad, 15, 169-190.

Genç, M., F., Avest, I., T., \& Miedema, S. (2011). Religious education in two secular multicultural societies: The Turkish and Dutch case compared. Procedia-Social and Behavioral Sciences, 15, 801-805. http://dx.doi.org/10.1016/j.sbspro.2011.03.188

Gorski, P. G. (2009). What we're teaching teachers: An analysis of multicultural teacher education coursework syllabi. Teaching and Teacher Education, 25(2), 309-318. http://dx.doi.org/10.1016/j.tate.2008.07.008

Herr, K., \& Anderson, G. L. (2005). The action research dissertation: A guide for students and faculty. Thousand Oaks, CA: Sage.

Johnson, A. P. (2005). A short guide to action research. Boston, MA: Pearson Education.

Kim, D. J., Park, Y. J., Cho, J. I., \& Kim, D. (2013). General and specific characteristics of a university-school partnership: Promoting learning opportunities for students with deafness or hearing impairments. International Education Studies, 6(1), 57-62.

Malakolunthu, S. (2000). Culturally responsive leadership for multicultural education: The case of "Vision School" in Malaysia. Procedia - Social and Behavioral Sciences, 9, 1162-1169. http://dx.doi.org/10.1016/j.sbspro.2010.12.301

McAllister, G., \& Irvine, J. J. (2000). Cross cultural competency and multicultural teacher education. Review of Educational Research, 70(1), 3-24. http://dx.doi.org/10.3102/00346543070001003

Milner, H. R., Flowers, L. A., Moore, E., Jr., Moore, J. L., III, \& Flowers, T. A. (2003). Preservice teachers' awareness of multiculturalism and diversity. The High School Journal, 87(1), 63-70. http://dx.doi.org/10.1353/hsj.2003.0018

Ray, A., Bowman, B., \& Robbins, J. (2006). Preparing early childhood teachers to successfully educate all children: the contribution of four-year undergraduate teacher preparation programs. Chicago, IL: Erikson Institute. Retrieved from http://www.erikson.edu/PageContent/en-us/Documents/pubs/Teachered.pdf

Rogers, D. A., Cater, A., Clambey, G. K., Garrison, M., Hanson, R. A., Harrold, R. L., ... Lindgren, H. E. (1993). Education for interdisciplinary, multicultural, and international understanding. Proceeding of the $23^{\text {rd }}$ Annual Frontiers in Education Conference. Washington, DC. http://dx.doi.org/10.1109/FIE.1993.405558 
Spradley, J. P. (1980). Participant observation. Orlando, FL: Harcourt College Publishers.

Thurston, A. (2004). Promoting multicultural education in the primary classroom: Broadband videoconferencing facilities and digital video. Computers \& Education, 43(1), 165-177. http://dx.doi.org/10.1016/j.compedu.2003.12.011

Trent, S. C., Kea, C. D., \& Oh, K. (2008). Preparing preservice educators for cultural diversity: How far have we come? Council for Exceptional Children, 74(3), 328-350.

Watanabe, T. (2010). Education for Brazilian pupils and students in Japan: Towards a multicultural symbiotic $\begin{array}{llllll}\text { society. Procedia - Social and Behavioral Sciences, } & \text { 7, }\end{array}$ http://dx.doi.org/10.1016/j.sbspro.2010.10.024

Woolf, M. (2010). Another Mishegas: Global citizenship. The Interdisciplinary Journal of Study Abroad, 15, $47-60$.

\section{Appendix}

The 2012 Institute of Early Childhood Education Forum Schedule

\begin{tabular}{|c|c|}
\hline Date & Topic \\
\hline Oct. 5 & Understanding how to Teach Korean language to Preschoolers \\
\hline Oct. 12 & $\begin{array}{l}\text { Understanding how to Teach K-6 children Korean language with technology use and how to } \\
\text { communicate with Korean parents }\end{array}$ \\
\hline Oct. 19 & $\begin{array}{l}\text { Learning Korean Language \& Culture with the Lens of Early Childhood Education through } \\
\text { Playing Korean Children's Songs and Music }\end{array}$ \\
\hline Oct. 26 & Comparing Korean Elementary Education with United States Elementary Education \\
\hline Nov. 2 & Learning from the History: History of Korean Kindergarten \\
\hline Nov. 9 & The History of Korean Language and Korean Children's Songs I \\
\hline \multirow[t]{2}{*}{ Nov. 16} & Survival Korean Language \& Culture \\
\hline & With Korean Children's Songs II \\
\hline \multirow[t]{2}{*}{ Nov. 30} & Sharing My Learning Experience of the Forum \\
\hline & \& presenting Survival Korean Language or Songs \\
\hline
\end{tabular}

